\title{
A luta dos(as) Guarani e Kaiowá em Mato Grosso do Sul por Kunã Aranduhá
}

\author{
Cláudia Regina Nichnig \\ Universidade Federal da Grande Dourados (UFGD), Brasil \\ E-mail: claudianichnig@ufgd.edu,br \\ ORCID: https://orcid.org/0000-0002-9689-8112 \\ Paula Faustino Sampaio \\ Universidade Federal de Rondonópolis (UFR), Brasil \\ E-mail: paulafaustinosampaio@hotmail.com \\ ORCID: https://orcid.org/0000-0002-3993-5060
}

Data de recebimento: 07/06/2020

Data de aprovação: 22/07/2020

DOI: https://doi.org/10.30612/frh.v22i39.12579

Jaqueline Gonçalves Porto, Kunã Aranduhá na língua guarani, é uma jovem liderança Guarani e Kaiowá. À importância de ser uma liderança feminina combatente em tempos tão sisudos e violentos para os povos tradicionais do Brasil, soma-se o fato de Aranduhá se constituir uma das protagonistas e organizadoras da Grande Assembléia de Mulheres Indígenas Guarani Kaiowá, a Kunangue Aty Guassu, que acontece anualmente nas terras indígenas em Mato Grosso do Sul, acolhendo mulheres indígenas de diferentes tekohas para a discussão de agendas específicas das mulheres. Essa entrevista foi realizada em setembro de 2019, nas dependências da Universidade Federal da Grande Dourados, onde Jaqueline é uma liderança também entre os(as) estudantes indígenas. Ela formou-se recentemente em Ciências Sociais e iniciou recentemente o mestrado em Antropologia Social, na mesma instituição. Sobre as suas vivências, sua experiência de militância indígena e sobre os feminismos é que conversamos, principalmente buscando refletir de que forma a atuação de uma jovem liderança indígena e feminista provoca (ou não) mudanças na produção do conhecimento, nas práticas educacionais e nas relações entre estudantes indígenas e não indígenas. Buscando trazer provocações a partir dos estudos indígenas e da epistemologia feminista, faz críticas à ciência colonial androcêntrica. Nossa conversa explicitou a força e a vibração dessa militante Guarani Kaiowá, feminista e mãe, que tem muito o que nos ensinar com sua força e perseverança, principalmente com a humildade e o respeito que tem com seu povo, sobretudo em relação às mulheres de diferentes gerações. 
Entrevistadoras: Bom dia. Eu sou Claúdia Nichnig. Vou começar uma entrevista aqui na Universidade Federal da Grande Dourados. Gostaria que tu falasse teu nome completo, local e data de nascimento.

Jaqueline: Meu nome é Jaqueline Gonçalves. Meu nome indígena é Kunã Aranduhá. Eu sou do povo Kaiowá, estado do Mato Grosso do Sul.

Entrevistadora: Você é estudante em que instituição e qual curso?

Jaqueline: Eu estudo na Universidade Federal da Grande Dourados, no curso de Ciências Sociais.

Entrevistadoras: Jaque, o que você gostaria de destacar em relação a sua infância e adolescência.

Jaqueline: A minha infância na Reserva Indígena de Dourados foi após os seis anos de idade. Antes disso, o meu pai servia como mão de obra aos fazendeiros da região. Eu e minha família viemos para a Reserva Indígena de Dourados quando eu tinha seis anos, para que eu pudesse estudar. Eu cresci na Reserva Indígena de Dourados, onde se encontra a segunda maior população indígena do país, são os Guarani e Kaiowá; um espaço de confinamento, que hoje se encontra aproximadamente dezessete mil Guarani e Kaiowá. Da minha adolescência foi uma fase bem complicada, porque meu pai foi assassinado quando eu tinha 13 anos. Muita coisa mudou com a morte do meu pai. E quando eu tinha 14 anos eu saí de casa. Então, eu praticamente amadureci. Tive o amadurecimento forçado nesse sentido. Mas eu sempre pensei em estudar, sempre pensei em lutar. E parte de minha militância hoje é em busca de justiça, de direitos, pro meu povo que é um direito que está cada vez mais distanciado. A gente fica o tempo todo lembrando que nós existimos, que temos direitos. É isso.

Entrevistadoras: Jaque, o que é feminismo para ti?

Jaqueline: Primeiro é uma palavra que não tem uma tradução na nossa língua. É uma palavra não indígena. Eu entendo mais do feminismo não indígena. Uma luta pelos direitos das mulheres, mas existem pautas dentro do feminismo que tenho certeza estão distantes da realidade das mulheres indígenas. Entendo uma pauta em um sentido do feminismo no sentido do feminismo da América Latina. Porque, inclusive, há um grito de guerra do feminismo que toda a América Latina vai ser feminista. Mas entendo que o feminismo ainda está longe de 
atingir todas as demandas de mulheres, incluindo as diferenças de cor, de classe econômica, religião e etc

Entrevistadoras: Em relação às teorias feministas, de quais leituras e perspectivas teóricas você se aproximou no teu ativismo?

Jaqueline: Sobre as perspectivas teóricas, uma das autoras que eu admiro bastante que é a Judith Butler, Simone de Beauvoir e tem a feminista nigeriana Chimamanda Ngozi Adichie, que eu curto bastante. São teóricas que eu super curti, que me identifico. São leituras difíceis, leio, releio, até compreender. São escrita de mulheres não indígenas, são escritas de pessoas de fora. São pessoas tentando entender o mundo que a gente vive, falando sobre ele de uma forma crítica. E, por enquanto são essas perspectivas teóricas que me identifiquei, que mais me aproximei nesse sentido.

Entrevistadora: Sobre os grupos que você participa.

Jaqueline: Participo de vários ... Várias discussões. Várias rodas de conversas na universidade, nas aldeias, nos acampamentos, nas reservas. Acredito que ainda temos dificuldades, de nós mulheres indígenas se organizarmos, entre nós. Primeiro que somos atravessadas por um processo histórico, desde a chegada dos Jesuítas para os quais as mulheres indígenas foram consideradas como meio de reprodução humana, e os homens indígenas foram considerados como mão de obra. E nesse meio, as mulheres ficaram muito submissas aos homens. Então entendo que as consequências disso ainda seguem muito fortes. E, as mulheres ainda tem dificuldade de caminhar, de trilhar seus próprios caminhos, de organizar grupos só delas. Mas eu não vejo isso como um problema também. Por exemplo, a Kuñangue Aty Guassu, que é a Grande Assembleia das Mulheres Guarani e Kaiowá, é um evento que é construído por elas, mulheres Guarani e Kaiowa. Todos os coletivos estão presentes, incluindo as crianças, os jovens, os idosos, incluindo as Nandesy, Nanderu, parteiras, comunidade em geral. A gente curte muito que os homens parem para nos ouvir porque a gente ficar falando entre nós não adianta, é necessário que os homens escutem para que não reproduzam mais violências contra mulheres. É essencial a participação dos homens, mas que eles fiquem na escuta nesse sentido. E tem funcionado.

Entrevistadoras: Dentro da Universidade tem um grupo que tu fazes parte? 
Jaqueline: Dentro da Universidade eu tenho dificuldade de participar dos grupos feministas porque justamente eu não me enquadro no discurso, no que defendem. Porque uma questão é você defender um discurso e não exercer na prática. Eu gosto muito que defendam um discurso, mas que exerçam na prática. A prática é muito importante. Assim, eu vejo poucas mulheres não indígenas que defendam e faz sem medir esforços e sem cobrar por isso. E a gente tem vários tipos de militância também. E o que segue mais forte hoje é a militância pela internet. Mas a gente como indígena a gente privilegia os encontros frente a frente. As falas frente a frente. E, esse negócio de internet não dá para encaminhar muita coisa.

Entrevistadoras: E em relação aos grupos das mulheres indígenas que você participa já destacou a questão das violências. Quais outros temas são discutidos por vocês hoje?

Jaqueline: A gente tem discutido bastante a questão das crianças indígenas, o abuso em todos os sentidos contra as crianças. $\mathrm{O}$ abuso contra as meninas. As diferentes violências contra as mulheres indígenas. A questão da demarcação que é uma violência grave do Estado contra o nosso povo. Mesmo que defendam que não existe um genocídio eu entendo que existe um genocídio contra os povos indígenas, pois a retirada de direitos de um povo, significa a sua morte. A morte de um povo, a retirada de direitos de um povo, por exemplo passar com a avião com equipamentos de veneno próximo de um povo que deixa eles doentes. $\mathrm{O}$ envenenamento das terras indígenas, como o caso da comunidade Apika'y deve ser considerado um genocídio. A gente tem discutido bastante a questão territorial. A questão do meio ambiente é uma pauta emergencial que a gente tem debatido bastante, inclusive estamos nos organizando. No nosso trabalho de formiguinha, de arrecadar semente e mudas de árvores para que a gente saia distruindo e plantando nas áreas. Somos contra todas as queimadas. Não adianta só defender esse discurso e não fazer nada. Tenho certeza da nossa função como defensoras da natureza, ainda mais quando vemos o que acontece na Amazônia, pois somos contra as queimadas. Nós temos uma relação com o meio ambiente muito profunda. As árvores, os rios, a terra tem o sentido de vida para nós. Não o sentido de mercadoria que é para esse Governo Federal. É, assim, que todo mundo que defenda que faça alguma coisa. Daí nesse sentido meio ambiente é uma pauta que a gente tem debatido bastante. Meio ambiente, a questão da violência obstétrica, a questão de uma saúde diferenciada para as mulheres. A gente tem a Sesai que é a Secretaria Especial de Saúde Indígena, mas que vem pregando um desmonte, que não respeita as nossas especificidades. E novamente a Kuñangue ela vem dizer para a Sesai que a partir do momento que os profissionais de saúde entram em campo eles 
precisam entender que lidam com povo, que tem uma cultura, uma cor de pele, uma tradição, costumes diferentes. Sendo assim, não levem para a aldeia aquilo que você aprendeu na universidade, na academia. Isso pode ser útil sim, claro, mas antes de tudo respeite a cultura de um povo porque é uma violação tudo que vem de cima, tudo que vem de fora pronto já para ser implantado na aldeia e não ser construído com eles, com o nosso povo. E não funciona. Assim como a Lei Maria da Penha, que é uma lei que a gente tem debatido muito. A gente tem feito críticas a Lei Maria da Penha. É a única lei que tenta minimizar os tipos de violências no país contra as mulheres indígenas. É uma lei maravilhosa, porém ela não de aptada a realidade das mulheres indígenas. Quando foi construída não teve escuta das mulheres indígenas para ter um parágrafo ou um algum momento na lei que haja um termo específico para as mulheres indígenas de acordo com a realidade delas. Muitas coisas como a medida protetiva ela deixa de existir quando se trata de mulheres indígenas. Os nossos temas que a gente tem debatido, a questão territorial, violência, meio ambiente, a questão da saúde materna da mulher indígena e dentro outros. Ai nesse meio nós tentamos nos fortalecer entre nós, enquanto mulheres indígenas. E pautamos também que nós que estamos a frente da organização e de toda essa construção que tem acontecido. Nós também estamos na mira da bala. Deixamos claro isso, porque toda e qualquer pessoa que levanta e que enfrente o Estado em tempos do que está acontecendo nesse país agora são pessoas na mira da bala. Nós tentamos nos fortalecer também entre nós para que a gente se mantenha viva nesse estado onde é muito forte a questão do agronegócio, de posse das nossas terras.

Entrevistadoras: Jaque, gostaria de que tu falasse um pouco de como foi toda essa articulação para organizar essa assembleia, a Kuñangue Aty Guassu.

Jaqueline: A Kuñangue Aty Guassu é uma organização de mulheres Guarani Kaiowá. Se não me engano é uma organização mais antiga de mulheres. Até então a gente vai para oitava assembleia em 2020. É tem sido difícil, desgastante construir uma assembleia. Mas o perfil da Kuñangue a gente sempre deixa algo para comunidade. Em 2017 a gente fez em uma área de retomada Kurusu Amba, área de fronteira, em 2018 fizemos numa aldeia onde se encontra o maior número de parteiras que foi em Panduí em Amambaí. E esse ano a gente realizou a assembleia em Yvy Katu, uma área de fronteira, uma área de retomada. E para construir tudo isso a gente primeiro busca recursos. E para construir tudo isso primeiro buscamos os recursos, para realizar uma Assembleia há um custo, em torno de 54 mil reais, contando transporte, contando alimentação, contando a hospedagem que são os acampamentos. A gente 
tenta garantir o máximo de número de mulheres, mas a gente não deixa de fora os homens também. E para fazer essa assembleia precisa de toda uma articulação primeiro de arrecadar grana e depois que a gente arrecadar a grana a gente consegue atribuí-la de acordo com as necessidades. No caso com transporte que sempre é das prioridades que é o mais caro. E ai tem toda uma metodologia Kaiowá que a gente segue. A proposta é que os nossos convidados não indígenas tenham um maior contato com a terra. Nessa assembleia eu vi muitos não indígenas em contato totalmente com a terra fazendo oficinas no chão, na terra, entendeu. Dormindo lá com a gente. Sentindo o que a gente sente. Dai eu vejo um retorno positivo de muita gente dizendo gratidão, foi uma aula. Essa sensação são muito positivas. A Kuñangue tem um planejamento de um ano para acontecer, em seis meses buscamos os recursos e nos outros seis meses a gente constrói uma assembleia. Tudo que é muito lindo custa muito trabalho para uma equipe de mulheres que somos em sete. Somos em sete mulheres tentando dar conta de um povo do Cone Sul. Tivemos a sorte que entrou mais duas que se colocaram a disposição de entrar nessa loucura com a gente de tentar construir. Mais tem toda uma articulação. Algumas meninas ficam somente para mapear as parteiras, as mulheres lideranças, as Nandesy, as Jaris; outras meninas ficam somente para a questão local, limpeza, construção de acampamento, colocar água, enfim, montar uma estrutura. Outras pessoas ficam só no financeiro que é fazer orçamento, o que está mais caro, o que está mais barato. Outras pessoas ficam só pagando, entendeu. Essa parte do só pagando é difícil porque a partir do momento que você entra na aldeia vem um monte de demandas, e dentro da aldeia não tem nota fiscal. Enfim, e outras pessoas ficam só responsáveis pela metodologia das mesas, de convite, de quem vai participar, de quem vai falar, quem vai ouvir, entendeu. E a gente sempre privilegia essa parte da escuta porque a gente cansa muito de falar e o poder público não nos ouve. Todas e todos que estão lá presente que representa de alguma forma poder público, que represente a universidade, que representa que são os nossos apoiadores. Antes de tudo a gente coloca eles como escuta. Que é o único espaço que a gente tem. Se não for ali, não tem outro espaço, outro momento que é específico para nos ouvir, que é bem difícil isso.

Entrevistadoras: Tu tens ou teve alguma articulação com grupo de esquerda ou de partido político?

Jaqueline: Não, nós não temos nenhum contato com partidos políticos porque nós acreditamos que eles acabam atrapalhando as nossas atividades, porque você fica preso e precisa defender o que o partido defende. O movimento Guarani Kaiowá, o movimento das 
mulheres, a Kuñangue Aty Guassu a gente não defende nenhum partido político. Todos os governos nos violaram de alguma forma. A tese do marco temporal que é a tese que diz que só tem direito a terra quem estava nela em 1988. A gente não estava porque a gente foi expulso na década de 1910 em diante, entendeu?! Então é uma tese que segue forte nesse governo que tem no congresso nacional uma bancada forte ruralista que defende a aprovação dessa tese do marco temporal. Não defendemos nenhum partido político, mas se eles quiserem dialogar com a gente é bem-vindo, a gente não defende mas tentamos dialogar com eles porque de alguma forma porque a gente precisa que o Estado nos ouça. O Estado precisa ouvir nossas demandas, nossas recomendações em forma de documento final de toda assembleia a gente encaminha. Mas não é nesse sentido de defender um partido, é mais no sentido deles receberem as nossas demandas.

Entrevistadoras: Jaque, em relação a tua participação como aluna aqui na universidade, você gostaria de destacar alguma disciplina, alguma atividade que você fez, que discutiu questões feministas e de gênero?

Jaqueline: Dentro da universidade, eu sempre fiquei muito curiosa em relação a todas as atividades. Tentando sempre me inserir, mesmo que muitas vezes eu não sentisse pertencer aquelas atividades, aquele grupo, mas muitas coisas me incomodaram na universidade. Todo ano a gente tenta trazer para UFGD uma discussão sobre a questão indígena no mês de abril. $\mathrm{E}$ isso tem sido bem interessante onde os acadêmicos e professores param para nos ouvir. Mas assim, eu me formo esse ano e espero que continue isso ano que vem porque é importante.

Entrevistadoras: Então, tu achas que tu participação como militante provocou algum tipo de mudança na universidade?

Jaqueline: Eu acredito que sim porque hoje as mulheres indígenas, acadêmicos em geral, tão sendo um pouco mais assistido. A gente enfrentou ano passado, ano de 2018 e esse ano também, vários acadêmicos em situação de fome, acadêmicos indígenas. A gente fez grupos denunciando. Denunciamos e discutimos em nível de universidade. Hoje eles estão sendo atendidos de alguma forma. De alguma forma é válida sim. Inclusive as pessoas me perguntam: - Jaque, o que tu faz serve de alguma coisa para ti? Para mim não, mas eu fico feliz que para eles sim. Porque hoje estão recebendo bolsas, kit alimentação, estão tendo transporte. E nenhum desses itens eu tenho. Mas enfim, bom que está atendendo eles porque tem umas situações dentro da universidade que são silenciosas mas existem. E tudo isso se 
não for atendido causa desistência. E, enfim, em tempos de crise o que salva a gente é o estudo.

Entrevistadoras: Que tu achas da predominância de ter textos de autores homens na academia?

Jaqueline: Aí, eu me incomodo bastante com isso porque dentro do curso de ciências sociais eu vejo poucas professores estudando mulheres, obras que mulheres escreveram. Eu me incomodo bastante com isso. E tento trazer dentro das aulas as discussões, mas assim, eu curto bastante os autores das ciências sociais, entretanto seguiria outra linha e seria mais proveitoso se abordássemos a perspectiva da mulher. São vários autores discutindo sobre capitalismo, são vários autores tentando desconstruir a questão moderna, pós-moderna, discutindo antropologia, discutindo sobre indígena. Todos homens, isso me incomoda, isso me incomoda bastante. Eu costumo dizer que vir para universidade estudar ciências sociais, estudar o mundo dos brancos, está numa sala que é para os não-indígenas, estudar livros e teorias que é dos não indígenas, fazer provas, e você tem que ler e entender aquilo que você tem uma prova mas são todos os autores não indígenas e autores homens, isso me incomoda, me incomoda bastante. Tem os autores que eu não consigo estudar assim. Daí eu vejo um resumo quando está chegando a prova só para tentar dar conta, mas eu não concordo com o planejamento de aula, que se repete todo ano, feito só de autores homens, brancos, falando de corpo indígenas, corpos negros, corpos femininos, e etc. Acho que a discussão seria melhor se os próprios falassem sobre eles também.

Entrevistadoras: Por isso que tu estás aqui! Queria perguntar como tu pensas, articulas, as lutas identitárias específicas de mulheres negras, indígenas e lésbicas em relação as lutas feministas?

Jaqueline: Essse ano 2019 foi o ano onde na $7^{\text {a }}$ assembleia foi que a gente tocou no assunto "lésbica" dentro de uma assembleia, diante de uma plenária de anciãs, jovens, homens, crianças, comunidade etc. E porque não tem mais como a gente não dá a visibilidade para a questão lésbica porque hoje tem muitas pessoas que se identificam como lésbicas, gays, e são indígenas e sofrem triplamente as violências em seus corpos. Então, não tem como a gente discutir direitos e deixar eles de lado. Seria uma violência também não discutir. É um assunto que a gente tenta levar mais devagar, porque a gente compreende os processos históricos das Nande su. As Nandesy parte não aceita, parte estão curiosas e parte já compreende. A gente 
busca aquelas que compreendem para tentar se unir a nós e para tentar explicar para outras que tudo são pessoas porque existe uma ignorância e preconceito do próprio indígena contra o indígena. Há uma defesa de um casamento hétero. Muitas pessoas que se identificam como gays, lésbicas. E pela primeira vez a gente colocou no documento final essa questão. A gente abordou em um documento final de uma assembleia Guarani Kaiowá a questão das lésbicas, gays, dentro das aldeias. Para mim isso foi um avanço; foi a primeira vez dentro de uma assembleia foi erguida uma bandeira LGBT com as cores LBGT, Marielle presente. A gente tem aos pouco trazido essa questão porque é uma questão visível, a gente está dando uma visibilidade em nível geral, em nível do cone sul é uma questão invisível. A gente deu um pouco de visibilidade, inclusive tivemos situações não muito boas que aconteceram durante o evento, de um casal de namoradas lésbicas que deu maior problema dentro do evento. E de alguma forma as Nandesy, as anciãs lidaram com isso. Outras Nandesy defendiam que viessem um homem e mostrasse para elas o que é um relacionamento hétero, enquanto outras Nande su vieram e falaram não vai fazer isso, ela não gosta disso, ela gosta disso. Elas conversando entre elas. Você entendeu? Isso significa que a gente precisa cada vez mais pautar essas questões.

Entrevistadoras: Gostaria que você falasse sobre a relação entre a Kunangue, a audiência pública recentemente vivenciada e a maternidade.

Jaqueline: A gente desde 2017 vem insistindo bastante na pauta do parto humanizado. E quando a gente fala em parto humanizado inserimos as Nandesy, parteiras, na discussão. Nós conseguimos realizar a audiência pública e trazê-las, que trouxeram junto seus remédios, falaram sobre os cuidados, antes, durante e pós parto. Elas falaram sobre o corpo das mulheres indígenas, sobre a importância do cuidado com a criança. Sobre o ritual tradicional que toda criança indígena tem que ter porque isso é válido para saúde, pra vida, para o fortalecimento, para resistência dessa criança. De 2017 para 2019 tivemos um grande avanço. Eu fico muito feliz com isso, de entidades públicas que estão trazendo a questão do parto humanizado, que está discutindo a questão da violência obstétrica, está convidando parteiras para está presente, e são resultados que a Kunangue alcançou. Eu fico muito feliz, tem muitas pessoas que mesmo de uma maneira distante recebem nossas demandas, realizam eventos; entram em contato conosco pedindo o contato de Nandesy para discutir sobre medicina tradicional, sobre o parto, sobre o corpo da mulher indígena. Teve um avanço positivo nesse sentido. Ainda essa semana mesmo eu vi fôlder que parece inspirado na nossa programação, 
que é um encontro de parteiras que estavam chamando para discutir a medicina tradicional, valorização das parteiras, em uma aldeia que não é entre os Guarani e Kaiowá. Então assim, a gente fica feliz porque a Kunangue dá uma visibilidade muito grande nesse sentido, o que acho de extrema importância diante de todo retrocesso que a gente está vivendo, do desmonte de tudo aquilo que construímos, de um enfrentamento inclusive de nosso direito de existir, nosso direito de ser mulher, de ser mãe, nosso direito de ser quem a gente é. É nesse contexto turbulento que nós estamos conseguindo dar toda essa visibilidade através de uma assembleia, através de uma audiência, então hoje as Nandesy tem uma agenda bem lotada, incluindo eventos, viagens etc. Assim estão dizendo o tempo todo que existem; tentando dizer o tempo todo pra nós que o que importa é nossa medicina tradicional, que precisamos defender o meio ambiente, que precisamos defender as parteiras, que a medicina não indígena precisa ser escuta da medicina Guarani Kaiowá, que o corpo da mulher indígena precisa de um cuidado diferentes, que uma mulher indígena gestante ela precisa receber os cuidados diferentes, ela precisa de uma cuidado tradicional. Nessa parte a gente está bem feliz que a gente avançou bastante; as pautas elas continuam além da assembleia e tem vários encontros nacionais que elas fazem, que foram convidadas para discutir tudo isso. A gente cumpre de alguma forma nosso dever que é dar voz as mulheres que não tem voz. Hoje elas estão tendo, mas dentro do hospital ainda tem uma resistência. O hospital não acredita nessa cura tradicional. A psicologia quando uma mulher tem algum problema psicológico pós-parto a psicologia trata como um surto. Aí nós somos diferentes. Nós tratamos isso como um espírito que está no corpo dela, um espírito mal, por que existe o (recovai) que é o mal, são coisas que se apossam do corpo e fazem com que a mulher tenha todos aqueles sintomas, mas a psicologia ignora totalmente isso e diz que a mulher está em surto, em surto pós parto; não param para ouvir a medicina Guarani Kaiowá. Eu ainda não vi nenhuma roda de discussão onde a medicina não indígena sentasse para ouvir a medicina Guarani e Kaiowá. Seria uma honra se isso acontecesse, seria uma honra ser escuta, mas não, isso não acontece. Enquanto isso não acontece a gente continua insistindo nas pautas, continuam insistindo nas pautas mesmo o hospital ainda não aceitando, mesmo acontecendo tudo que a gente já falou na audiência pública que as mulheres chegam no hospital são tratadas de uma forma muito preconceituosa, o hospital ainda é uma instituição muito racista. Existe um racismo institucional enraizado muito forte no hospital. É um espaço estranho, um quarto branco. Um monte de gente a sua volta, sendo que é diferente. Na aldeia quando a mulher vai dar a luz é ela e a parteira. Ela e os cuidados da parteira. Onde ela quiser, no quarto dela, na casa dela, no mato. E existe todo 
um olhar, uma discussão quando a criança nasce, por exemplo, quando a criança nasce o médico logo pega pelo pé, enfia um negócio pelo nariz, bate na bunda, a criança fica de cabeça para baixo. Com as Nandesy é diferente. Neném nasce, elas limpam. Neném já nasce com uma reza delas. Enrolada num pano, tem todo um ritual, inclusive da placenta que é enterrada. A placenta não é jogada no lixo. Alias, não sei o que fazem com a placenta no hospital. Mas claro, eles não guardam e não enterram. Existe um ritual. Mas há uma resistência muito grande da medicina não indígena de ouvir a medicina indígena porque se ouvisse, se juntasse, os cuidados pelo menos amenizariam todos esses tipos de violências que acontece contra o nosso corpo. Nós costumamos dizer que quando vidas vão dar vida à vida.

Entrevistadoras: Como é teu trabalho no hospital universitário? O que você percebe em relação ao trabalho do hospital de atendimento das mulheres indígenas?

Jaqueline: Eu costumo dizer que eu estou apagando fogo, onde está pegando fogo eles chamam a Jaqueline. E por várias vezes me chamaram na maternidade já para conversar com mulheres que já tiveram cinco, seis filhos e não queria tomar anticoncepcional. Mas no olhar do hospital elas tinham que tomar o anticoncepcional. Aí eles indicam muito implanon, que é um tipo de anticoncepcional que é colocado de forma subcutânea e tem uma duração de três anos. Daí tem todo um processo histórico. A geração da minha mãe elas tiveram 9, 12 filhos ou até mais, elas queriam. Essa geração agora é uma geração que tenta ter menos filhos. Mas ainda tem mulheres que querem ter filhos independente de classe econômica, elas querem ter filhos. Mas o hospital não entende, o hospital acha que elas têm que colocar o implanon para não ter mais filhos. Eu entendo até certo ponto que as mulheres precisam se cuidar, mas precisa respeitar se ela não quer tomar o anticoncepcional, ela não quer. A gente sempre deixa isso claro. Nós temos a nossa medicina indígena e a medicina não indígena. A pessoa tem a opção, quer ir pro hospital, quer ser cuidado pelo médico ou quer ir para um rezador, ser cuidado por um rezador, pela rezadora, pela Nandesy. A mesma coisa sobre o anticoncepcional. Quer tomar? Tem ali disponível, é público, não se paga. Mas se não quiser também, é opção da mulher. O corpo é dela, ela que responde. Eu costumo dizer que o Estado quer responder pelo corpo dela, quer colocar o implanon. Aí me chamam lá para fazer a mediação, eu simplesmente falo. Tem isso, existe essa opção, quer colocar? Não. Eu olho para enfermeira e falo, não, ela não quer colocar, entendeu. Por várias vezes já me chamaram na maternidade também para mediar quando a mãe solteira chega. A mãe solteira chega, ela é menor de idade, ela chega no hospital, tem o neném e o hospital trata como violência que ela 
é menor de idade, tipo, ela foi estuprada. Ela engravidou, é resultado de um abuso sexual, essa é a visão do hospital, parece que é uma burocracia que eles precisam seguir, aí eu vou lá conversa com ela e ela diz não, tinha um namorado e engravidei. A importância de falar a língua é essencial, a importância de ser escuta porque a rotina da maternidade é um rotina bem pesada também. Poucos conseguem ser escuta, está fazendo o que tem que fazer, todo o processo que é feito no corpo, inclusive esquecem de explicar. E por várias vezes fui chamada na maternidade também porque ultimamente aumentou o número de mulheres indígenas que chegam com pré-eclampsia, outras seguidas de eclampsia e pré-eclampsia, entre 22 semanas e 32 semanas, o neném nasce prematuro e vai direto para UTI. Claro, o nascimento se dá através do parto cesariana. Aumentou o número de cesariana, aumentou o número de eclampsia, aumentou o número de nenezinho que nasce e vai direto para UTI. Dai as mães têm que ficar no hospital, um, dois, três, até quatro meses aos cuidados do médico, ela não tem nenhum acampamento tradicional. Não tem nenhum chá, nenhuma erva para ela tomar, pro cuidado do corpo dela, e ela ai na rotina estressante do hospital. O resultado da préeclampsia com certeza vem de muito agrotóxico, muito agrotóxico, muita violência no espaço das aldeias. E é isso, acho.

Entrevistadoras: Queria que tu falasse um pouco da centralidade do atendimento da mulher enquanto mãe. Que há uma centralidade na questão da maternidade, da maternagem. E a mulher solteira e a mulher que não tem uma relação heterossexual, como é o atendimento?

Jaqueline: Isso é bem visível nos hospitais né. Por mais que sejam heteras, sejam lésbicas, é uma mulher indígena que chegou. Elas não tem o mesmo acolhimento lá no hospital. E eu já vi situações em que a família inteira veio para visitar a puérpera e o recém-nascido e não deixaram entrar porque estava suja, estava acompanhado por bebê, etc. Será que não compreendem que a gente está num estado onde a terra é vermelha, os indígenas ainda cozinham no fogo, onde não temos o que todo mundo tem, que é cozinhar no fogão, que é ter um piso em casa, é que é diferente, é uma realidade diferente, é indígena, é não indígena. Já presenciei muitas pessoas que chegam assim na recepção e antes de ser internada mandam tomar banho, mandam tomar banho. Já presenciei várias situações onde as mulheres estão na recepção e o remédio tradicional não entrou, ficou lá, um Mbaraká não entrou, ficou lá, tipo, fica lá preso com o guardinha. Ai o que entra? A pessoa só e pouca coisa entra. Então, é um racismo institucional muito forte. 
Entrevistadoras: E para finalizar, a partir de tu perspectiva você pensa alguma proposta de ensino pro Brasil? Você gostaria de deixar uma mensagem final em relação à educação?

Jaqueline: Eu acredito muito na educação acima de tudo, porém acredito que está bem distante do Brasil queresr discutir a questão indígena dentro da sala de aula. Tendo, por exemplo, uma disciplina no ensino fundamental de histórias indígenas, que chamasse indígenas nas universidades, vamos conversar antropologia, a questão indígena, a visão do autor é essa. Vamos fazer uma contribuição, um contraponto, a visão de um Nanderu, que Nanderu e Nandesy são professores, mas não existe isso. É o não indígenas falando de novo de livros escritos por não indígenas para não indígenas, mas falando de índio. Eu acho que colocar mais a temática indígena de uma forma que atenda as nossas demandas, tendo nós junto, porque uma coisa é falar do não indígena a partir das teorias dos livros sem o indígena por perto, mas é muito válido também ter indígenas, na verdade ter indígena em todos os locais, em todas as discussões, em todas as disciplinas. Porque o que valoriza hoje é tudo que foi construído pelo não indígena e pouco se valoriza. Ai depois diz que não indígena não dá valor a cultura etc., mas se nem nos espaços que a gente frequenta somos obrigados a frequentar não é, por exemplo, Universidade Federal da Grande Dourados, curso de Ciências Sociais, eu estou no oitavo semestre, último semestre do curso Ciências Sociais, nenhuma vez, nenhum professor chamou Nanderu ou Nandesy numa aula de antropologia. Aonde é minha aula de antropologia? Na assembleia. Não existe. E olhe que nós estamos aqui do lado de uma aldeia que tem a segunda maior população indígena do país, estamos do ladinho, e nenhum professor se dá ao trabalho de levar os calouros pra fazer uma visita, a não, leva no MST, tipo levam em outros lugares, em outras universidades, mas é aqui do lado, mostrem para eles que tem aqui do lado, que estamos aqui do lado, que tem os acampamentos, que Damiana está ali, que temos sete acampamentos aqui e que temos a Bororó e a Jaguapiru, não levam, mas discutem a questão indígena, entendeu. Está tendo agora um encontro de etnologia guarani, em São Paulo, isso é para facilitar ou para dificultar nosso acesso enquanto estudantes? E eles enquanto comunidade? Está falando deles de alguma forma, mas cadê eles nesse sentido? É isso.

Entrevistadoras: Obrigada, Jaque. 